Check for updates

Cite this: RSC Adv., 2017, 7, 27260

\title{
Fabrication and characterization of hydrogels formed from designer coiled-coil fibril-forming peptides $\uparrow$
}

\author{
A. F. Dexter, $t^{\star a}$ N. L. Fletcher, $\S^{a}$ R. G. Creasey, ${ }^{b}$ F. Filardo, $q^{a}$ M. W. Boehm ${ }^{b}$ \\ and K. S. Jack (D)*c
}

Hydrogels are soft solids that represent attractive matrices for tissue engineering, wound healing and drug delivery. We previously reported an $\alpha$-helical peptide, AFD19, that forms fibrils and hydrogels at pH 6, but precipitates under physiological conditions. We now show that a single targeted change in AFD19 yields peptide AFD36, which gels at physiological $\mathrm{pH}$ and in the presence of salt. Furthermore, we present a simple method for homogeneous sol-gel conversion through $\mathrm{pH}$ titration with sodium bicarbonate followed by loss of carbon dioxide. Chemical and thermal denaturation studies show AFD36 selfassembles to give stable $\alpha$-helical structures, forming fibrils of $3.8-3.9 \mathrm{~nm}$ diameter at $\mathrm{pH} 4.0-7.0$ as shown by small-angle $X$-ray scattering and atomic force microscopy. An AFD36 gel at 0.35\% (w/v) showed an elastic modulus of $350 \mathrm{~Pa}$. Mouse fibroblasts exhibited low cellular toxicity and spread morphologies when grown on the gel as a preliminary proof of principle towards cell culture studies. These peptide gels offer a molecularly simple, biodegradable alternative to polymer-based systems for biomedical applications.

Received 8th March 2017

Accepted 10th May 2017

DOI: $10.1039 / \mathrm{c} 7 \mathrm{ra02811c}$

rsc.li/rsc-advances

\section{Introduction}

Hydrogels are an area of burgeoning research interest, with an increasing number of papers reporting the preparation and characterization of these highly-hydrated soft solids. ${ }^{\mathbf{1 , 2}}$ Highvalue applications for hydrogels exist particularly in the biomedical field, ${ }^{3}$ where a range of chemistries have been tested for regenerative medicine,$^{4-6}$ drug delivery ${ }^{7,8}$ and wound healing. ,10 $^{10}$

Two classes of hydrogels - chemical and physical-can be distinguished in terms of the cross-links between the structural components. In chemical (chemically cross-linked) hydrogels, gel formation involves covalent cross-linking of polymer chains

\footnotetext{
${ }^{a}$ The University of Queensland, Australian Institute for Bioengineering and Biotechnology, Qld 4072, Australia. E-mail: a.dexter@uq.edu.au

${ }^{b}$ The University of Queensland, School of Chemical Engineering, Qld 4072, Australia ${ }^{c}$ The University of Queensland, Centre for Microscopy and Microanalysis, Qld 4072, Australia.E-mail: k.jack@uq.edu.au

$\dagger$ Electronic supplementary information (ESI) available: Thermodynamics of coiled-coil assembly. See DOI: 10.1039/c7ra02811c

\$ Present address: The University of Queensland, School of Agriculture and Food Science, Brisbane QLD 4072, Australia.

$\S$ Present address: The University of Queensland, Centre for Advanced Imaging, Australian Institute for Bioengineering and Nanotechnology and the ARC Centre of Excellence in Convergent BioNano Science and Technology, Brisbane QLD 4072, Australia.
}

I Present address: Department of Agriculture and Fisheries, Brisbane QLD 4102, Australia. into a three-dimensional network. Such gels typically possess a solid content in the range $5-15 \%(w / v)$, have high elasticity, and undergo an equilibrium swelling process. ${ }^{11-13}$ In contrast, physical (physically cross-linked) hydrogels rely on weak noncovalent interactions, such as hydrogen bonding, hydrophobic forces or charge-charge interactions, between structural components for network formation. ${ }^{\mathbf{1 4}}$ The preparation of physical hydrogels involves conversion of a sol to a gel state, typically by mixing components or a change in temperature; such gels cannot be prepared by equilibrium swelling of a solid. ${ }^{\mathbf{1 4 , 1 5}}$ Physical gels are commonly prepared at concentrations in the range $0.1-5 \%(\mathrm{w} / \mathrm{v})$ and have lower strength than chemical gels. ${ }^{\mathbf{1 , 5}, 16-18}$ Physical gels often display shear thinning with self-healing, making them more suitable for soft tissue engineering or as injectable media., ${ }^{2,19,20}$

Peptides are favorable starting materials for the preparation of physical gels, given their biodegradability, stimuli-responsiveness $^{21,22}$ and the possibility of rationally designing their selfassembly. ${ }^{16,23}$ The largest body of work to date on selfassembling peptide hydrogels has employed $\beta$-sheet motifs. ${ }^{17,18,24} \beta$-sheet peptides form fibrils in which component peptides align perpendicular to the fibril axis, held together by hydrophobic and hydrogen bonding interactions. Control of fibril self-assembly and gel formation can be achieved by control of peptide molecular charge, ${ }^{18,19}$ salt composition ${ }^{25}$ and solvent quality, ${ }^{17}$ yielding robust gels that have been successfully applied in a number of tissue engineering model systems. ${ }^{26,27}$ 
$\beta$-sheet assemblies have been investigated and used extensively for clinical applications. ${ }^{28,29}$ However, the core structure of $\beta$-sheet fibrils resembles amyloid or prion structures that occur in Alzheimer's and Parkinson's diseases, as well as a number of other less well-known disease states in which normal proteins refold into pathogenic structures in the presence of seed elements. ${ }^{30,31}$ Some reports have demonstrated the cross-seeding of amyloidogenic sequences by dissimilar amyloid structures. ${ }^{32,33}$ While there remains controversy as to the generality of these results, in at least one case, fibrils of designed peptides with amyloid-like properties were reported to induce amyloidosis, illustrating the potential for initiation of disease states by $\beta$-sheet gels. ${ }^{34}$

Another pathway to peptide hydrogels employs $\alpha$-helices that form extended coiled-coil fibrils in which the components align parallel to the fibril axis. Rational design work from the Woolfson group ${ }^{35}$ has yielded $\alpha$-helical peptides with forced offsets that self-assemble into insoluble thickened fibrils. The same group has reported peptide sequences that form thinner fibrils and hydrogels that support cell growth. ${ }^{16}$ In addition, several other researchers, including ourselves, have reported $\alpha$ helical peptides without forced offsets that form $\alpha$-helical fibrils and in some cases hydrogels. ${ }^{36-38}$ We have attributed such fibril formation to permissive, rather than forced, overlap of selfsimilar peptide sequences, ${ }^{36}$ and believe fibril formation of this kind may be a more widespread property of coiled-coil peptides than previously recognized.

In this study, a coiled-coil peptide designed to gel at physiological pH is characterized. The 21-residue peptide AFD36 was generated by a single amino acid change from the previously reported peptide AFD19. ${ }^{36}$ It is shown that this targeted change shifts gelation from $\mathrm{pH} 6.0$ to $\mathrm{pH} 7.4$, allowing gel formation to proceed under conditions favorable to mammalian cell growth. Slow and uniform gelation was achieved by titration with bicarbonate, permitting a handling window for the gelling peptide solution. Small-angle X-ray scattering (SAXS) data collected under varying conditions of $\mathrm{pH}$ are consistent with the formation of higher-order coiled-coil fibrils as the basis of the gel, with fibril formation confirmed using atomic force microscopy (AFM). Chemical and thermal denaturation studies show that the fibrils are extremely stable, a result which is attributed to the strong hydrophobic driving force for selfassembly. Oscillatory shear rheology results show the hydrogels to possess soft-solid properties. As a proof of principle, the peptide hydrogels were used to support the growth of mouse fibroblasts, making these materials promising candidates for tissue engineering applications.

\section{Experimental}

\section{Materials}

Reagents were of the highest grade available. Water was purified using an Elga Purelab Classic and had a resistivity of $>18.2$ $\mathrm{M} \Omega \mathrm{cm}$. Glassware was acid-cleaned as previously described. ${ }^{39}$ Peptides AFD19 (Ac-LKELAKV LHELAKL VSEALHA-CONH ${ }_{2}$, FW 2354) and AFD36 (Ac-LKELAKV LHELAKL VKEALHA-CONH ${ }_{2}$, FW 2395) were synthesized and purified by GenScript
(Piscataway, New Jersey). The final purity was $>95 \%$ in each case. The peptide content of the solid was determined by quantitative amino acid analysis (Australian Proteome Analysis Facility, Sydney). The charge on each peptide as a function of $\mathrm{pH}$ was estimated as described previously. ${ }^{36}$

\section{Plate reader assays}

Spectrophotometric determination of $\mathrm{pH}$ used an Infinite M200 plate reader (Tecan, Männedorf, Switzerland) with 48-well plates and sample volumes of $200 \mu \mathrm{L}$. The acidity constant of phenol red in Dulbecco's modified Eagle's medium (DMEM, Invitrogen) was determined by titration, with absorbance monitored at $433 \mathrm{~nm}$. Reference A433 readings for fully protonated and fully deprotonated phenol red were obtained by addition of $10 \mathrm{mN} \mathrm{HCl}$ and $10 \mathrm{mN} \mathrm{NaOH}$, respectively. $\mathrm{A} \mathrm{p} K_{\mathrm{a}}$ of 7.70 was obtained as the $y$-intercept of a plot of $\mathrm{pH} v s . \log \left(\left(A_{\text {acid }}\right.\right.$ $\left.\left.-A_{433}\right) /\left(A_{433}-\mathrm{A}_{\text {base }}\right)\right)$. The same $\mathrm{p} K_{\mathrm{a}}$ value was employed for peptide solutions in phosphate-buffered saline $(140 \mathrm{mM} \mathrm{NaCl}$, $5 \mathrm{mM} \mathrm{KCl}, 1.5 \mathrm{mM} \mathrm{Na}+$ phosphate, $60 \mu \mathrm{M}$ phenol red).

For gelling tests, $100 \mu \mathrm{L}$ of an AFD36 stock solution $(8.4 \mathrm{mM}$, $\mathrm{pH} \sim 3$ ) was mixed in a 48-well plate with $100 \mu \mathrm{L}$ of an $\mathrm{NaHCO}_{3}$ solution in either $2 \times$ DMEM containing $80 \mu \mathrm{M}$ phenol red or $2 \times$ phosphate-buffered saline $(240 \mathrm{mM} \mathrm{NaCl}, 10 \mathrm{mM} \mathrm{KCl}, 3.0 \mathrm{mM}$ $\mathrm{Na}+$ phosphate) containing $120 \mu \mathrm{M}$ phenol red. UV-visible spectra $(700-350 \mathrm{~nm})$ were recorded at 3 min intervals over $60 \mathrm{~min}$ and single wavelength readings were extracted for analysis. Spectra showing an isosbestic point at $477 \mathrm{~nm}$ were used for $\mathrm{pH}$ calculations, while samples showing light scattering were excluded. For greater sensitivity, the $\mathrm{pH}$ of gelling samples was determined at $558 \mathrm{~nm}$, with pH calculated as $7.70+$ $\log \left(A_{558}-A_{\text {acid }}\right) /\left(A_{\text {base }}-A_{558}\right)$.

\section{Small-angle X-ray scattering}

SAXS data were collected using an Anton Paar SAXSess instrument which uses a monochromated $\mathrm{Cu}$ sealed anode operating at $40 \mathrm{kV}$ and $50 \mathrm{~mA}$, a line focus (Kratky) geometry and a CCD detector at a fixed sample-to-detector distance. Peptide samples were prepared at $5 \mathrm{mg} \mathrm{mL}^{-1}$ in $10 \mathrm{mM} \mathrm{Na}+$ acetate $(\mathrm{pH} 4.0$ or $5.0)$ or 2 -( $N$-morpholino)ethanesulfonate (MES; pH 6.0 or 7.0) with addition of $\mathrm{NaCl}$ to maintain an ionic strength of 0.01 . Samples were housed in a silica capillary maintained at $20{ }^{\circ} \mathrm{C}$ during the measurements. SAXS data were measured over a range of $q=0.007$ to $0.2 \AA^{-1}$ (where $q$ is the momentum transfer vector) and the data were reduced by standard procedures to remove the dark current and background measured from the buffer, after accounting for the relative transmission of the sample and background. The data were placed on an absolute intensity scale using the known cross section of water as a primary standard. ${ }^{40}$ The data presented represent the average of 1800 exposures collected for $10 \mathrm{~s}$ each to ensure that there were no changes occurring during exposure to the X-ray beam.

Analysis of the X-ray data was carried out using the NCNR analysis macros in Igor Pro. For the data obtained here, a flexible cylinder model was used to determine both the mean radius and persistence length of the fibrils as a function of $\mathrm{pH}$. 
In these models the electron density for the buffer was calculated to be $9.45 \times 10^{-6} \AA^{-2}$, while that for AFD36 was estimated to be $1.22 \times 10^{-5} \AA^{-2}$ based on chemical composition.

\section{Atomic force microscopy}

AFM micrographs were collected using an Asylum MFP3D SPM (Oxford Instruments) using NanoWorld FM probes (nom $k=2.8$ $\mathrm{N} \mathrm{m}^{-1}$, nom $f=75 \mathrm{kHz}$ ) in tapping mode under ambient conditions. Peptide samples were freshly prepared at $20 \mathrm{mg}$ $\mathrm{mL}^{-1}$ in water, then diluted to a final concentration of $5 \mathrm{mg}$ $\mathrm{mL}^{-1}$ in MES buffer with final concentration of $10 \mathrm{mM}$ (pH 6). 5 $\mu \mathrm{L}$ of sample was quickly spotted onto mica and immediately removed, and allowed to dry in air overnight before imaging. Image analysis was undertaken using freeware Gwyddion (http://gwyddion.net) v2.41 and ImageJ v1.5 (http:// imagej.nih.gov/ij/).

\section{Electronic circular dichroism (ECD)}

ECD spectra were recorded on a Jasco J-815 spectropolarimeter in $0.1-1 \mathrm{~mm}$ quartz cuvettes. AFD36 spectra were recorded at $20{ }^{\circ} \mathrm{C}$ using $1.75 \mathrm{mM}$ peptide self-buffered at $\mathrm{pH} 7.0$ (gel) or 3.1 (sol). Heating-cooling studies were carried out at $20-90{ }^{\circ} \mathrm{C}$ at a heating rate of $1.5^{\circ} \mathrm{C} \mathrm{min}{ }^{-1}$, using $0.84 \mathrm{mM}$ AFD36 in $10 \mathrm{mM}$ MES $\mathrm{pH}$ 7.0. Peptide solutions for chemical denaturation studies were prepared at $250 \mu \mathrm{M}$ peptide in $10 \mathrm{mM} \mathrm{Na}+$ acetate pH 5.0 (AFD19) or $10 \mathrm{mM}$ MES pH 6.0 (AFD36) containing 0-8 M guanidinium chloride (G.HCl), and were equilibrated at 20 or $50{ }^{\circ} \mathrm{C}$ before recording ellipticity at $222 \mathrm{~nm}$. Raw ellipticity was converted to mean residue ellipticity by normalizing for path length and the concentration of peptide bonds.

\section{Gel melting}

A ball drop test was conducted using a stainless steel ball $(6 \mathrm{~mm}$ diameter; $1.0 \mathrm{~g}$ ) placed on the surface of a AFD36 gel heated in a water bath. The gel was prepared by mixing $4.2 \mathrm{mM}$ AFD36 in $10 \mathrm{mM}$ MES with $22.5 \mathrm{mM} \mathrm{NaHCO}$ (final concentrations), and was allowed to stand overnight before the heating test to allow loss of $\mathrm{CO}_{2}$ and complete setting. The gel was heated from 30 to $80{ }^{\circ} \mathrm{C}$ in $10^{\circ} \mathrm{C}$ steps, and was held for $15 \mathrm{~min}$ at each temperature before being photographed. A separate test was conducted on an AFD36 gel prepared in phosphate-buffered saline at the same concentration. Gel melting $\left(T_{\mathrm{m}}\right)$ was recorded at the temperature where the ball dropped completely through the gel.

\section{Guanidinium chloride denaturation}

Thermodynamic analysis of peptide self-assembly in the presence of denaturant was based on an approach by Fairman, ${ }^{\mathbf{1 1}}$ adapted for a higher-order coiled-coil assembly. Various schemes were tested using pentamer, hexamer or heptamer states for the minimum coiled-coil assembly of AFD36 at $20{ }^{\circ} \mathrm{C}$, as well as a dodecamer based on end-to-end stacking of two hexamers. Given that similar thermodynamic results were obtained on a per-monomer basis for each of these oligomer models, only a hexamer model was used for comparison of AFD19 at $20{ }^{\circ} \mathrm{C}$ and AFD36 at $50{ }^{\circ} \mathrm{C}$.
Assembly of monomers to higher-order oligomers in the absence of denaturant was treated as a two-state system in which $K_{n, 1}$ is the equilibrium constant for disassembly of the coiled coil $(n=5,6,7$ or 12$)$ :

$$
K_{n, 1}=\frac{[\mathrm{mon}]^{n}}{[n-\mathrm{mer}]}
$$

and $\Delta G$ is the associated positive free energy change:

$$
\Delta G=-R T \ln K_{n, 1}
$$

The presence of guanidinium chloride (G.HCl) was taken to modify the free energy of peptide self-assembly in a linear fashion:

$$
\Delta G=\Delta G^{\left(\mathrm{H}_{2} \mathrm{O}\right)}+m[\mathrm{G} . \mathrm{HCl}]
$$

where $m$ has a negative value and acts to decrease the free energy penalty of coiled coil disassembly, thereby promoting denaturation. A more negative value of $m$ represents a larger effect of $\mathrm{G} . \mathrm{HCl}$ on peptide folding, and has been correlated with a greater change in accessible surface area on conversion of the folded to unfolded states. ${ }^{\mathbf{4 2}}$

For electronic circular dichroism, the contribution of monomers and $n$-mers to the ellipticity at a single wavelength (in this case, $222 \mathrm{~nm}$ ) is given by:

$$
[\theta]_{\mathrm{obs}}=[\theta]_{\mathrm{mon}} \times \frac{[\mathrm{mon}]}{[\mathrm{P}]_{\mathrm{tot}}}+[\theta]_{n-\mathrm{mer}} \times \frac{n \times[\mathrm{mon}]^{n}}{K_{n, 1} \times[\mathrm{P}]_{\mathrm{tot}}}
$$

where $[\theta]_{\text {mon }}$ is the mean residue ellipticity of the monomer and $[\theta]_{n \text {-mer }}$ the corresponding value for the $n$-mer. The monomer is taken to assume a random coil conformation with a mean residue ellipticity close to zero, while the $n$-mer is taken to be helical with a mean residue ellipticity that can be estimated from the helix length. ${ }^{\mathbf{4 3 4 4}}$ For chemical denaturation studies with G.HCl, in which the free energy of self-assembly is different at each denaturant concentration, eqn (4) was modified to give:

$$
\begin{aligned}
{[\theta]_{\text {obs }}=} & {[\theta]_{\text {mon }} \times \frac{[\mathrm{mon}]}{[\mathrm{P}]_{\text {tot }}}+[\theta]_{n \text {-mer }} \times \frac{n \times[\mathrm{mon}]^{n}}{\mathrm{e}^{\left(\frac{\Delta G^{\left(\mathrm{H}_{2} \mathrm{O}\right)}}{-R T}\right)} \times \mathrm{e}^{\left(\frac{m[\mathrm{G} . \mathrm{HCl}]}{-R T}\right)}} } \\
& \times \frac{1}{[\mathrm{P}]_{\mathrm{tot}}}
\end{aligned}
$$

For test values of $K_{n, 1}$ and $m$ for each value of $n$, values for the free monomer concentration [mon] are obtained by numerical fitting to the mass balance equation for the total peptide in solution, $[\mathrm{P}]_{\text {tot }}$, allowing assessment of the least-squares fit to the data:

$$
[\mathrm{P}]_{\mathrm{tot}}=[\mathrm{mon}]+\frac{n \times[\mathrm{mon}]^{n}}{\mathrm{e}^{\left(\frac{\Delta G^{\left(\mathrm{H}_{2} \mathrm{O}\right)}}{-R T}\right)} \times \mathrm{e}^{\left(\frac{m[\mathrm{G} \cdot \mathrm{HCl}]}{-R T}\right)}}
$$

Best-fit values of $\Delta G^{\left(\mathrm{H}_{2} \mathrm{O}\right)}, m,[\theta]_{\text {mon }}$ and $[\theta]_{n \text {-mer }}$ obtained for each test value of $n$ are given in Table S1 of the ESI. $\dagger$ 


\section{Gel rheology}

Rheological measurements were carried out at $23{ }^{\circ} \mathrm{C}$ on a Thermo Scientific Haake MARS III stress-controlled rheometer using parallel plates ( $35 \mathrm{~mm}$ titanium) at a gap of $500 \mu \mathrm{m}$; the top plate had emery paper attached to limit slip. To prepare a gel, $500 \mu \mathrm{L} 2.8 \mathrm{mM}$ AFD36 pH 3 was mixed with $500 \mu \mathrm{L} 25 \mathrm{mM}$ $\mathrm{NaHCO}_{3}, 2 \times$ DMEM and loaded onto the lower plate using a micropipette, after which the upper plate was lowered. To limit evaporation, drops of water were placed in the solvent trap around the outer edge of the lower plate and a hood was lowered to cover the plates; the water drops were not in contact with the sample. A transient oscillatory test was used to capture development of structure as the $\mathrm{pH}$ rose with loss of $\mathrm{CO}_{2}$ from the sample, permitting gelation. The angular frequency was set to $6.28 \mathrm{rad} \mathrm{s}^{-1}$ for quick measurements and the oscillatory shear stress was set to $0.1 \mathrm{~Pa}$, which gave strain less than 0.005 . Relative to the final gel, an oscillatory shear stress of 0.1 Pa was well within the linear viscoelastic region. The oscillation time test was run for 3600 seconds and measurements commenced within 5 minutes of peptide mixing.

An oscillatory stress sweep at an angular frequency of 6.28 $\operatorname{rad} \mathrm{s}^{-1}$ was then run on the same sample, to determine the linear viscoelastic region. Using an oscillatory shear stress of 0.1 $\mathrm{Pa}$, an oscillatory frequency sweep was also run from 0.29 to $19.9 \mathrm{rad} \mathrm{s}^{-1}$.

\section{Mammalian cell culture}

NIH/3T3 cells (CRL-1658, ATCC) were maintained in DMEM (Gibco, Life Technologies) supplemented with $10 \%$ (v/v) newborn calf serum (Ausgenex, Australia). Cultures were kept at $37{ }^{\circ} \mathrm{C}$ in a humidified $5 \% \mathrm{CO}_{2}$ incubator.

To remove residual by-products from solid-phase peptide synthesis, solutions of AFD36 were stirred with $8 \mathrm{M}$ urea and $3 \mathrm{mg} \mathrm{mL} \mathrm{mL}^{-1}$ activated charcoal for 24 hours. Charcoal was removed by centrifugation at $20000 \mathrm{~g}$ for 45 minutes and filtering $(0.2 \mu \mathrm{m})$. The solution was then dialyzed against $0.1 \mathrm{M}$ $\mathrm{NaCl}(24 \mathrm{~h})$ and water $(2 \times 24 \mathrm{~h})$. Recovered peptide $(2.8 \mathrm{mM})$ was adjusted to $\mathrm{pH} 3$ and sterile-filtered $(0.20 \mu \mathrm{m})$ then stored at $-80{ }^{\circ} \mathrm{C}$ until use. To prepare gels for cell culture, $50 \mu \mathrm{L}$ acidic peptide solution was mixed thoroughly with $50 \mu \mathrm{L} 25 \mathrm{mM}$ $\mathrm{NaHCO}_{3}, 2 \times$ DMEM (initially bicarbonate free) in individual wells of a 48-well tissue culture plate. Samples were allowed to gel for $1 \mathrm{~h}$ at RT then transferred to an incubator and soaked for $2 \times 2$ days in serum-free DMEM $(500 \mu \mathrm{L})$ before seeding with $\mathrm{NIH} / 3 \mathrm{~T} 3$ cells at $10^{4}$ cells per well. Control wells contained NIH/ 3T3 cells seeded onto tissue culture polystyrene (TCPS) alone. Cell growth was quantified using AlamarBlue (Life Technologies) at days 1-4 $(n=3)$. Fluorescence readings used a Tecan Infinite M200 plate reader with $\lambda_{\text {ex }} 560 \mathrm{~nm}$ and $\lambda_{\text {em }} 590 \mathrm{~nm}$. Fluorescence values for cell-free wells were subtracted from the values of cell-containing wells. Statistical analyses used Student's $t$-test, with differences considered significant for $p$ values of $<0.05$. Cell images were taken at $10 \times$ magnification at day 3 .

\section{Results and discussion}

\section{Peptide design}

We have previously reported the design of a 21 residue $\mathrm{pH}$ responsive $\alpha$-helical peptide, AFD19 (Ac-LKELAKV LHELAKL VSEALHA-CONH${ }_{2}$ ), that forms self-healing gels at pH 6.0 and weight fractions as low as $0.1 \%$. Here, it is shown that a single designed change in AFD19 yields a new peptide, AFD36 (AcLKELAKV LHELAKL VKEALHA-CONH${ }_{2}$ ), that gels under physiological conditions of $\mathrm{pH}$ and salt.

Fig. 1 illustrates the peptide AFD36 as a higher order coiledcoil $n$-mer. Canonical coiled coils are based on an abcdefg heptad repeat ${ }^{45,46}$ in which positions $a$ and $d$ comprise the hydrophobic core of the coil and are typically occupied by aliphatic amino acid residues such as leucine (L), valine (V) or isoleucine (I). AFD19 and AFD36 are three-heptad peptides conforming to this general pattern, where the flanking positions $e$ and $g$ are populated with additional aliphatic amino acids, including helix promoting alanine (A). This yields an expanded hydrophobic core that provides a strong driving force for self-assembly, leading to a highly thermodynamically stable coiled coil. ${ }^{47-49}$ At the same time, an expanded hydrophobic core tends to lead to formation of higher-order (tetramer and larger) coiled coils, ${ }^{45}$ as suggested for AFD19. ${ }^{36}$

For geometric reasons, higher-order coiled coils contain an internal tubular cavity, as observed in heptamer, ${ }^{47,50}$ hexamer, ${ }^{49}$ pentamer $^{51}$ and even tetramer ${ }^{51,52}$ structures.

The outward-facing surface of the AFD36 coiled coil at positions $b, c$, and $f$ is occupied by hydrophilic residues, primarily helix-favoring cationic lysine (K) and anionic glutamate $(\mathrm{E})$ residues, but also histidine residues $\left(\mathrm{H} ; \mathrm{p} K_{\mathrm{a}} \sim 6\right)$ intended to confer $\mathrm{pH}$-responsiveness in self-assembly. The sole

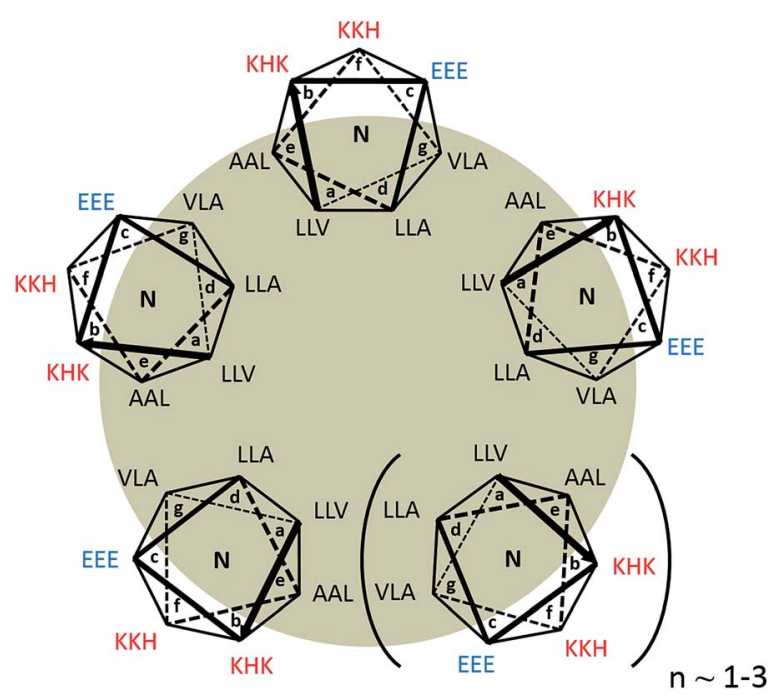

Fig. 1 Structure of AFD36 modeled as a parallel coiled-coil $n$-mer. L, V and $A$ residues comprise an expanded hydrophobic core at positions $a$, $d$, e and $g$ of the abcdefg heptad repeat. Charged residues occupy positions $b, c$, and $f$, which face the aqueous medium. For clarity, cationic residues are in red, anionic in blue, and the hydrophobic core is shaded. 


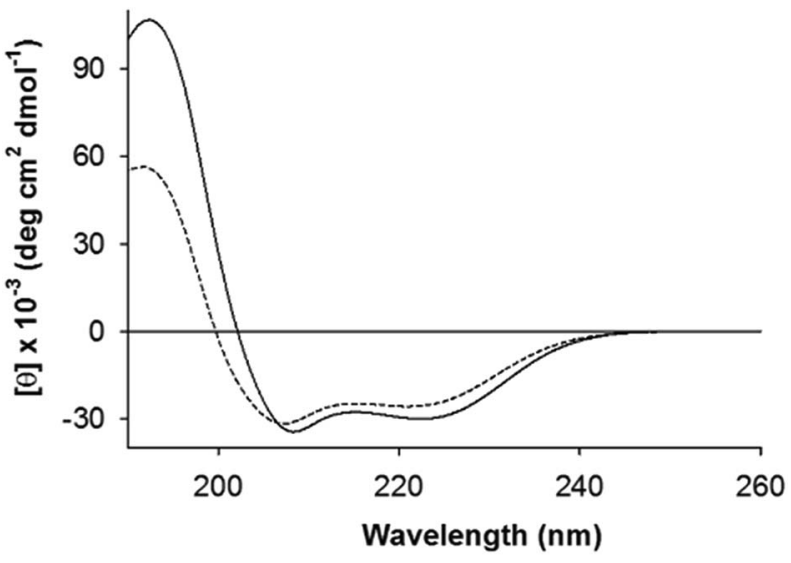

Fig. 2 Electronic circular dichroism (ECD) spectra of self-buffered AFD36 in gelled and non-gelled states. Solid line, pH 7.0 (gel); dashed line, $\mathrm{pH} 3.1$ (sol). The peptide concentration was $1.6 \mathrm{mM}$.

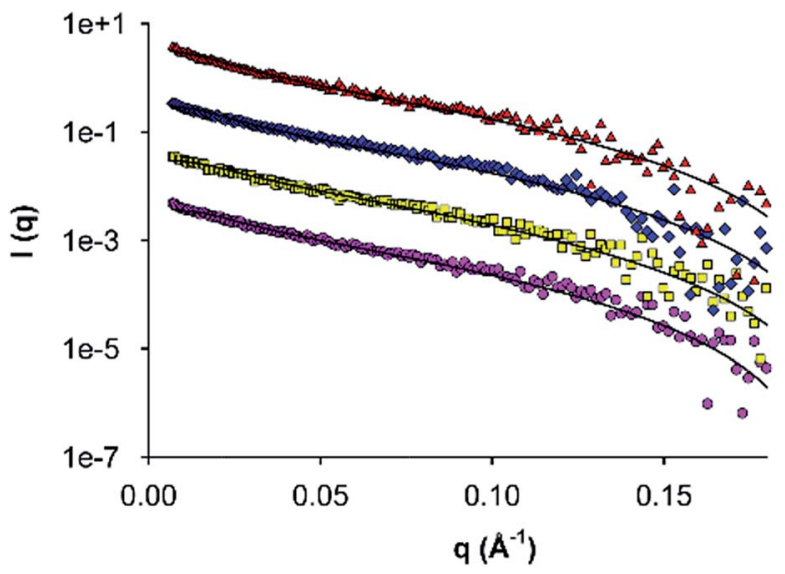

Fig. 3 Small-angle $X$-ray scattering by self-assembled AFD36 fibrils. Data were collected for $0.5 \%(\mathrm{w} / \mathrm{v})$ peptide at $\mathrm{pH} 4.0$ (pink circles), 5.0 (yellow squares), 6.0 (blue diamonds) and 7.0 (red triangles). Solid lines indicate fits to a flexible cylinder model. Data sets above $\mathrm{pH} 4.0$ are displaced upwards progressively by a factor of ten for clarity.

Table 1 Diameter of AFD36 fibrils at different $\mathrm{pH}$ values as obtained from SAXS

\begin{tabular}{lll}
\hline $\mathrm{pH}$ & Fibril diameter $(\mathrm{nm})$ & $\begin{array}{l}\text { Persistence } \\
\text { length }(\mathrm{nm})\end{array}$ \\
\hline 4.0 & $3.91 \pm 0.05$ & $10.6 \pm 1.4$ \\
5.0 & $3.82 \pm 0.05$ & $10.7 \pm 2.1$ \\
6.0 & $3.79 \pm 0.05$ & $14.0 \pm 0.3$ \\
7.0 & $3.78 \pm 0.05$ & $12.4 \pm 3.5$
\end{tabular}

difference between AFD19 and AFD36 is the presence of a lysine rather than an uncharged serine residue $(\mathrm{S})$ at position 16, meaning that at physiological $\mathrm{pH}, \mathrm{AFD} 36$ carries a single positive charge, sufficient to prevent large aggregate formation while permitting gelation based on the physical association of fibrils.
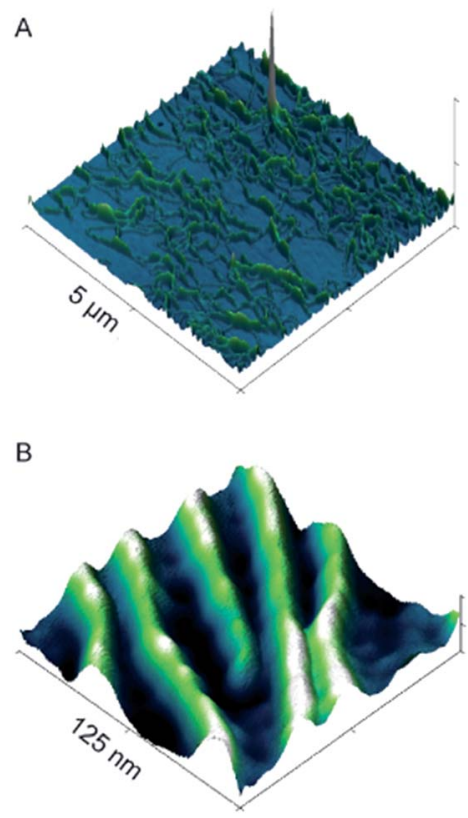

Fig. 4 AFM 3D micrographs of AFD36, prepared from $5 \mathrm{mg} \mathrm{mL}^{-1}$ concentration under fibril-forming conditions (10 mM MES; $\mathrm{pH}$ 6) at (A) micron (5 $\mu \mathrm{m} x$-scale, $20 \mathrm{~nm} z$-scale) and (B) nanometer scale (125 nm $x$-scale, $3 \mathrm{~nm} z$-scale).

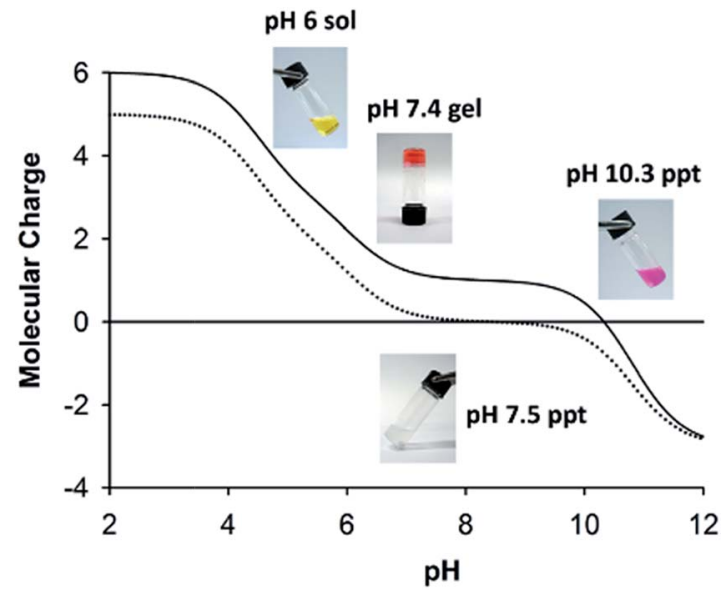

Fig. 5 Gelation as a function of $\mathrm{pH}$ and molecular charge for AFD36 and parent sequence AFD19. Calculated charge curves are given for AFD36 (solid line) and AFD19 (dotted line). Inset: photographs of sol, gel and aggregate states for AFD36 (top) and aggregate state for AFD19 (bottom). Phenol red has been included in the self-buffered AFD36 samples as a visual indicator of $\mathrm{pH}$. The peptide concentration was $2.0 \mathrm{mM}$ for AFD36 and $1.2 \mathrm{mM}$ for AFD19; above critical gelling concentration.

$\alpha$-Helices in which $e$ and $g$ sites are populated by oppositelycharged residues are generally expected to form parallel coiled coils due to charge-charge repulsion in the antiparallel arrangement. ${ }^{53}$ While the $e$ and $g$ sites in AFD19 and AFD36 are occupied by non-polar residues, a similar argument may be applied to the $b$ and $c$ flanking positions ${ }^{54}$ making it likely that these peptides assume a parallel structure. 


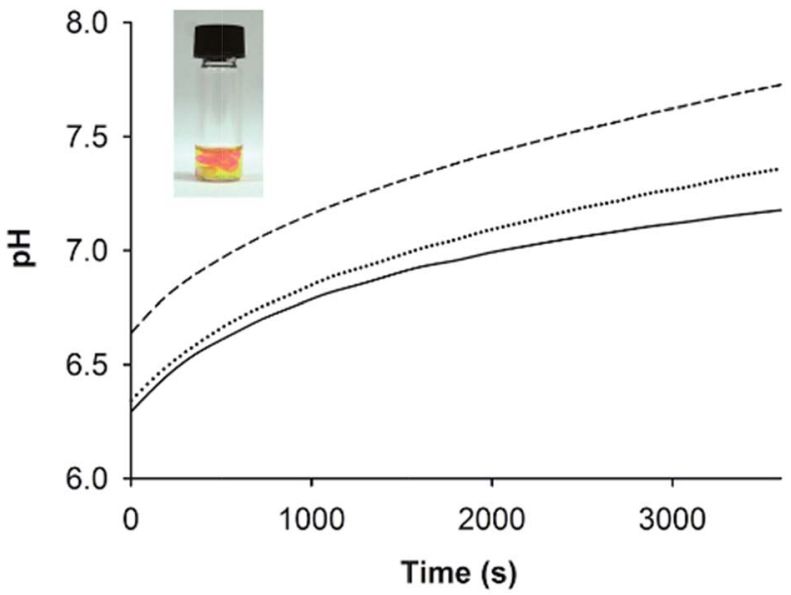

Fig. 6 pH changes over time for AFD36 gels prepared in model serum salts upon titration with different concentrations of bicarbonate. Solid line, $10.0 \mathrm{mM} \mathrm{NaHCO}$; dotted line, $11.2 \mathrm{mM} \mathrm{NaHCO}$; dashed line, $12.5 \mathrm{mM} \mathrm{NaHCO}$. Inset: local gelling with $\mathrm{pH}$ inhomogeneity on titration of AFD36 with $\mathrm{NaOH}$. The peptide concentration in each case was $2.1 \mathrm{mM}$

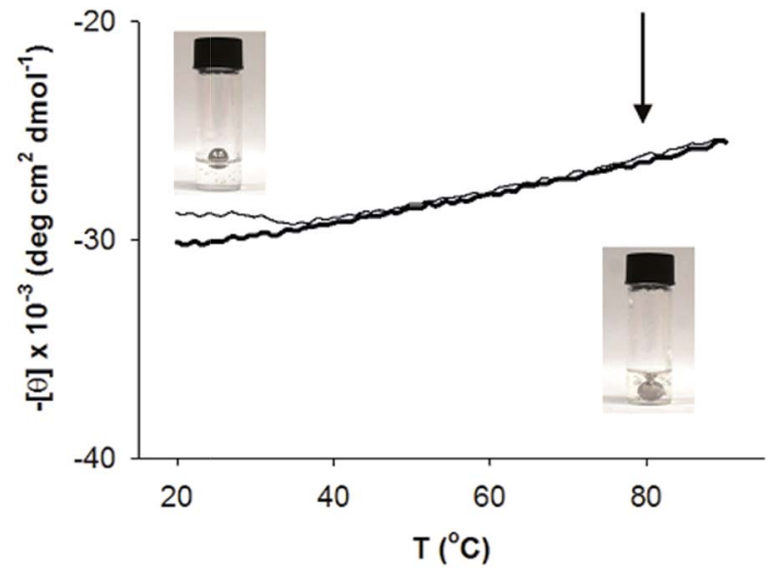

Fig. 7 Thermal stability of secondary structure for $0.84 \mathrm{mM}$ AFD36 in $10 \mathrm{mM}$ MES pH 7.0. Thick line, heating curve; thin line, cooling curve. Inset: determination of the gel melting temperature via a ball drop test with photos taken at $30^{\circ} \mathrm{C}$ (upper left) and $80^{\circ} \mathrm{C}$ (lower right). Arrow indicates $T_{\mathrm{m}}$. The peptide concentration was $4.2 \mathrm{mM}$.

In the absence of more structural information AFD36 is illustrated as a parallel coiled coil containing 5-7 base units in cross-section. This is consistent with the propensity for $\alpha$ helices with an expanded hydrophobic face to form higherorder coiled coils and the positioning of charged residues at $b$ and $c$ positions favoring a parallel arrangement. An oligomerization state larger than a heptamer is thought to be unlikely as higher oligomerization states have not been observed in designed peptide systems. ${ }^{45}$ This structure is also consistent with the observed fibril diameter and cooperativity of assembly of $\sim 6$ determined for the parent peptide AFD19. ${ }^{36}$

The designs reported herein complement the work reported by the Woolfson group, which has shown that designer coiledcoil peptides form elongated fibrils if elements are included
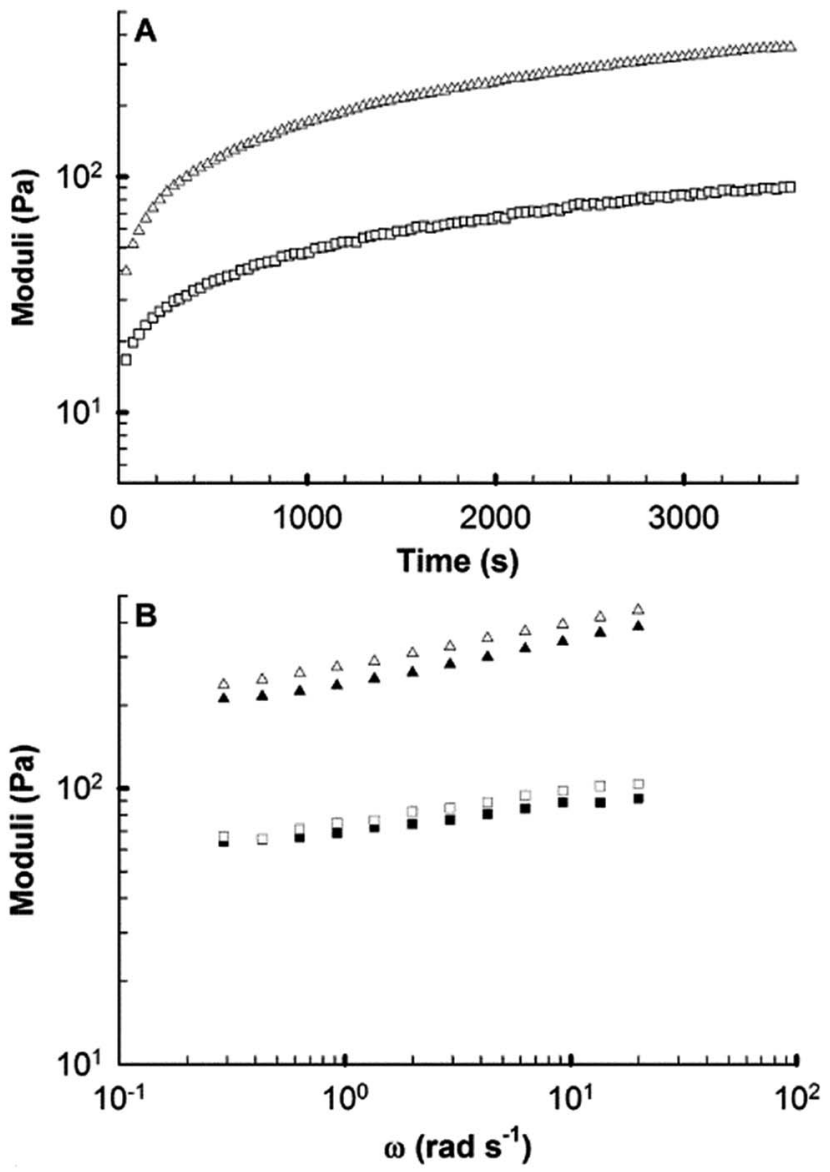

Fig. 8 Rheological characterization of a $0.35 \%$ (w/v) AFD36 hydrogel (A) over time during gelation ( $x$ axis is time from measurement initialization) and (B) as a function of frequency (two samples). In both plots $G^{\prime}$; triangles, $G^{\prime \prime}$; squares.

that force end-to-end overlapping of $\alpha$-helices. This approach has been used to prepare insoluble $\alpha$-helical fibrils with controllable morphologies ${ }^{55-57}$ and more recently, thin fibrils that form self-supporting gels. ${ }^{16} \mathrm{~A}$ similar approach, based on placement of polar residues within the coiled-coil core, has been reported by Zimenkov et al. ${ }^{58,59}$ Another system showing offsetting of helices was reported by Liu et al.,${ }^{47}$ who observed the peptide GCN4-pAA to form a heptameric coiled coil with a single-residue shift in registry between adjacent helices, resulting in an offset of a full heptad between helices 1 and 7 . Helix offsetting is likely driven by preferential packing of hydrophobic residues at positions $a, d, e$ and $g$, as well as a ring of hydrogen bonding residues within the coiled-coil core. $\mathrm{Xu}$ et al. ${ }^{50}$ more recently reported redesign of this peptide to give 7HSAP1. This peptide forms staggered coiled coils which are able to stack via end-to-end overlap of helices to give coiled-coil fibrils.

We have previously proposed another approach to coiled-coil fibril formation that is driven by permissive rather than specified helix offsetting. ${ }^{36}$ Included in this class are peptides AFD19 and AFD36 as well as the fibril-forming sequences of Kojima et al. ${ }^{60}$ Dong et al.,${ }^{61}$ Potekhin et al. ${ }^{48}$ and Melnik et al. ${ }^{37}$ which 

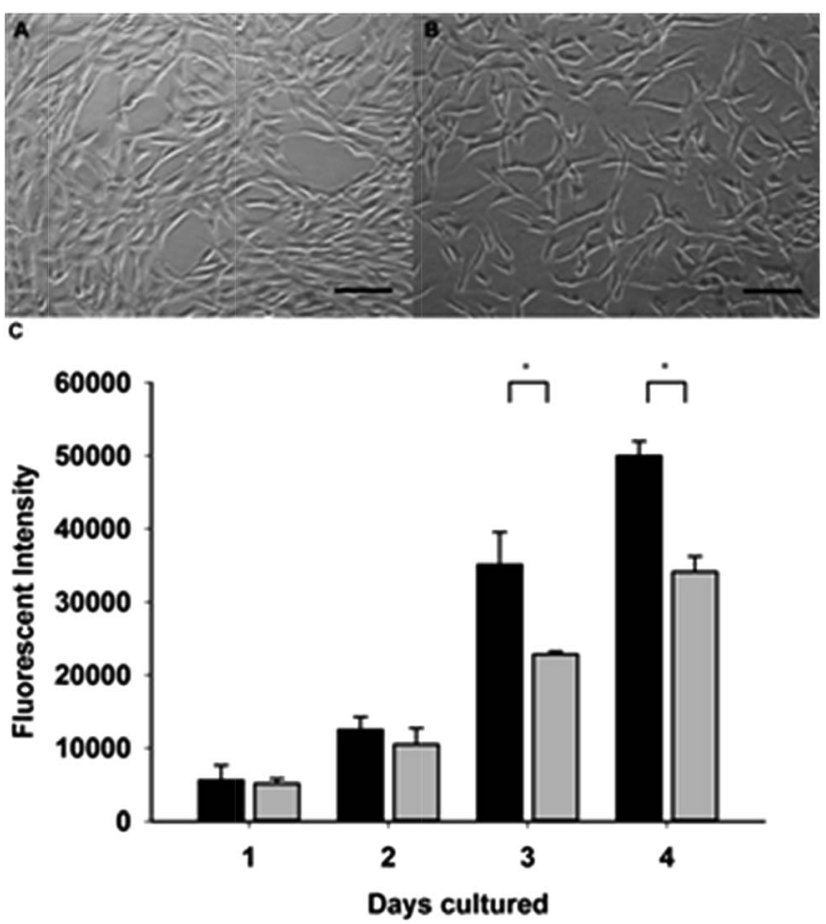

Fig. 9 Growth of 3T3 fibroblasts on AFD36 gels and TCPS controls Representative images of cells cultured on (A) TCPS control surface or (B) AFD36 hydrogel at 3 days (scale bar $100 \mu \mathrm{m}$ ). (C) Cell growth measured via AlamarBlue fluorescence assay on TCPS (black bars) and AFD36 hydrogels (grey bars) at $1-4$ days $\pm \mathrm{SD}(n=3)$. * $p$ values $\leq 0.05$ relative to the control, as determined by Student's $t$-test.

possess some broad similarities. These designed peptides lack forced offsets and have a high degree of self-similarity in the constituent heptad repeats. Importantly, the net intermolecular interactions of an $\alpha$-helix with self-similar heptad repeats are likely to be energetically similar for both an in-register arrangement and a staggered fibril with heptad offsets. Designs based on self-similar heptad repeats avoid the thermodynamically destabilizing ${ }^{52}$ placement of polar residues in the coiled-coil core, thereby facilitating development of gels composed of short single peptides, as opposed to paired peptides or longer sequences that may be expensive to synthesize. As exact repeats are not required for fibril assembly, this design approach still allows the incorporation of specific residues to control molecular charge, as was done here to achieve gelation at physiological pH. It also allows for diversity of residue composition, which may be useful in the context of peptide bioproduction.

\section{Self-assembly of coiled-coils and gels}

AFD36 self-assembles into a coiled coil as judged by electronic circular dichroism (ECD) spectroscopy. Fig. 2 shows ECD spectra for an AFD36 solution at pH 3.1 and a gelled sample at $\mathrm{pH}$ 7.0. The double minimum at 208 and $222 \mathrm{~nm}$ and maximum at $192 \mathrm{~nm}$ are characteristic of an $\alpha$-helix. Unlike AFD19, which gels at $\mathrm{pH} 6.0$ but forms aggregates at $\mathrm{pH}$ 7.0, the redesigned peptide forms transparent gels at $\mathrm{pH}$ 7.0. In the gelled state, the mean residue ellipticity at $222 \mathrm{~nm}$ is $-30100 \mathrm{deg} \mathrm{cm} \mathrm{dmol}^{-1}$, implying an $\alpha$-helical content close to $91 \%$ for AFD36 under these conditions. ${ }^{43}$ In contrast to AFD19, which has a similar helical content at $\mathrm{pH} 3.0$ and $\mathrm{pH} 6.0$ at low millimolar concentrations (comparable to those used here), ${ }^{36}$ AFD36 is less helical at $\mathrm{pH} 3.1$ than at $\mathrm{pH}$ 7.0. The difference may be due to the higher molecular charge in AFD36 (+6 for AFD36 vs. +5 for AFD19 at pH 3), leading to destabilization of the coiled coil by a greater degree of electrostatic repulsion.

Formation of a gel at low weight concentrations strongly suggests the formation of fibrils (as opposed to globular structures) as the basis of the gel. The shape of the ECD double minimum for AFD36 at $\mathrm{pH} 7.0$ is consistent with the formation of fibrils that are not thickened by lateral association. While early reports ${ }^{62,63}$ that coiled coils could be distinguished from monomeric $\alpha$-helices by a higher $[\theta]_{222} /[\theta]_{208}$ ratio appear to have been over-generalized, ${ }^{\mathbf{4 3 , 6 4}}$ high $[\theta]_{222} /[\theta]_{208}$ ratio are indeed seen in cases of fibril thickening, likely due to light scattering. ${ }^{16,55}$ No such spectral changes are seen for AFD36; the formation of optically clear gels at physiological $\mathrm{pH}$ also favors the interpretation that the fibrils are not aggregated.

\section{Fibril structure}

To further investigate fibril self-assembly by AFD36, SAXS data was obtained for AFD36 samples prepared at $\mathrm{pH}$ 4.0-6.0 (nongelled) and 7.0 (gelled). The data, with fits to a flexible cylinder model, are shown in Fig. 3. Fitted diameters and persistence lengths are given in Table 1 and are consistent with the formation of fibrils at each $\mathrm{pH}$, even though gelation is not seen below $\mathrm{pH}$ 7.0. The fibrils have similar properties across the entire $\mathrm{pH}$ range, with a diameter of 3.8-3.9 nm. From the current SAXS data, it is evident that the fibril diameter for AFD36 $(<4 \mathrm{~nm})$ is similar to that of observed using negative staining transmission electron microscopy (TEM) of AFD19 fibrils at acidic $\mathrm{pH},{ }^{36}$ and that bundling or thickening of AFD36 fibrils in solution does not occur in the $\mathrm{pH}$ range from 4.0 to 7.0. For comparison, Banwell et al. ${ }^{\mathbf{1 6}}$ have reported designer peptides with zero net charge that form bundled fibrils (as judged by electron microscopy and ECD) as well as opaque gels. It appears that the molecular charge on AFD36 at the $\mathrm{pH}$ values tested here prevents fibril bundling.

To better characterize fibril structure and dimensions, AFM was performed on samples prepared at pH 6. As shown in Fig. 4, fibrils were observed at pH 6 on the mica surface. AFD36 fibrils had a height of $3.5 \pm 0.9 \mathrm{~nm}(N=51)$ as measured by AFM. It is documented that the AFM imaging process may reduce the apparent height of biological molecules and in addition, the fibrils are in a dehydrated state. ${ }^{65}$ Hence, the AFM data is consistent with SAXS data.

Comparison of AFD36 fibril diameters with reported higherorder coiled coils shows observed sizes to be consistent with the proposed coiled-coil structure. Data from X-ray crystallography or nuclear magnetic resonance spectroscopy give approximate diameters of $3.1 \mathrm{~nm}$ for the designed peptide GCN4-pAA (seven strands; 2HY6), ${ }^{47} 3.0 \mathrm{~nm}$ for the M2 segment of the acetylcholine receptor (five strands; 1EQ8), ${ }^{66} 3.3 \mathrm{~nm}$ for the designed 
peptide CC-Hex (six strands; 3R48) ${ }^{49}$ and $2.9 \mathrm{~nm}$ for cartilage oligomeric matrix protein (COMP, five strands; 1VDF).$^{67}$ Redesign of GCN4-pAA has yielded peptide 7HSAP1, which forms fibrils with a proposed heptamer structure and a diameter of $3.0 \mathrm{~nm}$ as measured by X-ray diffraction. ${ }^{\mathbf{5 0}}$ The AFD36 fibrils, at 3.8-3.9 $\mathrm{nm}$ as measured by SAXS and $3.5 \mathrm{~nm}$ as measured by AFM, are slightly larger than these reference systems. The diameter of an $\alpha$-helix is not constant but instead dependent on residue composition. Therefore, the larger observed fibril diameter may in part be due to the higher content of larger aliphatic residues in AFD36 than are present in the comparison systems. Nonetheless, the diameter is still consistent with a fibril structure comprising unbundled higher-order coiled coils of at least a pentamer. In an effort to more precisely determine the minimum oligomer state of the peptide size exclusion chromatography was attempted under acidic conditions. At lower $\mathrm{pH}$, high molecular charge was expected to prevent fibril assembly; however, conditions were not able to be identified that gave discrete coiled-coil assembly in the absence of fibril formation. Chemical denaturation studies (below) also fail to distinguish between different oligomer states, but confirm that the fibrils are highly thermodynamically stable, apparently as a result of a strong hydrophobic driving force for self-assembly.

The persistence lengths of AFD36 fibrils as determined by SAXS may also be compared to those of other biomolecular systems. In the pH range from 4.0 (sol) to 7.0 (gel), AFD36 fibrils show a persistence length of 10-14 nm, indicating a flexible structure that does not alter over the sol-gel transition. For comparison, the persistence length of double-stranded DNA, with a hydrodynamic diameter of $3 \mathrm{~nm}$, lies in the range 50$100 \mathrm{~nm},{ }^{68}$ indicating that the DNA double helix has less flexibility than AFD36 fibrils. Fibrils of 1-6 nm diameter formed from the milk protein $\beta$-lactoglobulin have a persistence length of $90 \mathrm{~nm}$ to $4 \mu \mathrm{m}$ depending on $\beta$-sheet content, ${ }^{69}$ while amyloid-forming designer $\beta$-sheet peptides have persistence lengths of up to $70 \mu \mathrm{m}$ at a diameter of $8 \mathrm{~nm} \cdot{ }^{70}$ AFD36 fibrils are thus relatively flexible, which may relate to the non-specific character of hydrophobic interactions between the subunits in the fibril. Fibril lengths were also measured by AFM, with fibrils identified from $<100 \mathrm{~nm}$ to $>4 \mathrm{um}$ in length (average length $914.4 \pm 838 \mathrm{~nm}, N=81)$. Many fibrils were intertwined or were not fully visible within an image area (Fig. 4A); nonetheless, AFD36 fibrils show a very high aspect ratio.

\section{Charge-based control of gelation}

Formation of physical hydrogels involves a delicate balance between solubility of the main components and association between them. We have previously reported a "phase diagram" for formation of sol, gel and aggregate states by AFD19 as a function of $\mathrm{pH},{ }^{36}$ and have accounted for transitions between these states in terms of changes in the molecular charge. Fig. 5 shows a similar schematic for AFD36, with the charge curve for AFD19 included for comparison. At acidic $\mathrm{pH}$, both peptides form low-viscosity solutions, which convert to transparent hydrogels on titration with base. For AFD19, gel formation occurs at $\mathrm{pH}$ 6.0, where the molecular charge lies close to +1 . For AFD36, a similar charge is only reached at around $\mathrm{pH}$ 7.0, allowing gelation to proceed at physiological $\mathrm{pH}$. Both peptides form precipitates at $\mathrm{pH}$ values where the predicted molecular charge lies close to zero, but this occurs at $\mathrm{pH} 7.0$ for AFD19, while the equivalent state is not reached until $\mathrm{pH} 10.3$ for AFD36. Both peptides form a second gel phase at high $\mathrm{pH}$ (data not shown), where the molecular charge lies close to -1; Aggeli et $a l .{ }^{18}$ have similarly reported that a molecular charge of +1 or -1 is compatible with the gelation of $\beta$-sheet peptides.

Although we have not relied on intermolecular chargecharge interactions in the design of AFD19 and AFD36, we consider net molecular charge to be an important factor in control of fibril-fibril interactions, allowing inter-fibril association to drive gel formation while preventing fibril bundling that could lead to loss of solubility. Results with both AFD19 and AFD36 show that gel transitions occur at $\mathrm{pH}$ values close to a molecular charge of +1 or -1 , while loss of solubility occurs at a pH where the molecular charge approaches zero (Fig. 5). The morphology of the AFD19 or AFD36 aggregates formed at zero charge have not been examined, but it is reasonable to assume that they comprise bundles of the fibrils seen at nearby $\mathrm{pH}$ values, possibly resembling the fibril bundles formed by offset peptide designs with a zero net charge.$^{55-57}$ Development of a method that provides a handling window for $\mathrm{pH}$-responsive gelation is an important element in potential biomedical application of gels in this class, as it permits the formation of evenly-mixed gels, which can be otherwise difficult to prepare in fast-gelling systems.

Interestingly, both AFD19 and AFD36 gels appeared to selfheal after mechanical disruption on a time scale similar to the original gel formation. Gelation of AFD19 or AFD36 is also reversible with $\mathrm{pH}$ indicating that they may be suited for use in injectable gels.

\section{Uniform gelation via transient buffering}

One disadvantage of pH-responsive gelling systems is a tendency to mix poorly due to local gelation on addition of acid or base. This was observed with AFD36 gels prepared in the presence of $\mathrm{pH}$ indicator dyes (Fig. 6, inset). On addition of $\mathrm{NaOH}$ to an acidic peptide solution containing phenol red, a basic gel forms locally (crimson) that is surrounded by acidic medium (yellow). $\mathrm{pH}$ equilibration occurs slowly, leading to a non-uniform structure and lower gel strength; in extreme cases, gel formation may fail completely. To overcome this problem, a method of slow $\mathrm{pH}$ adjustment was developed based on transient buffering by carbon dioxide. The method gives a handling window for gelation of concentrated peptide solutions, while allowing uniform mixing to maximize gel strength. To achieve this, an acidic peptide solution is titrated with the weak base sodium bicarbonate leading to the formation of carbonic acid, which itself dissociates to give a slightly acidic solution $\mathrm{pH}$. Carbonic acid is in equilibrium with atmospheric carbon dioxide, meaning that it is gradually lost from the gelling solution, leading to a slow $\mathrm{pH}$ rise that can be observed using an indicator dye. 
UV-visible spectrophotometry and phenol red were used to track pH changes in AFD36 samples prepared in phosphatebuffered saline and titrated with different amounts of sodium bicarbonate; results are shown in Fig. 6. As would occur on titration with a strong base, the final $\mathrm{pH}$ depends on the amount of base added, but following addition of bicarbonate, $\mathrm{pH}$ change occurs as an initial step change followed by a slow drift upwards, with equilibration in a $200 \mu \mathrm{L}$ volume taking more than an hour. Clear gels are obtained at $\mathrm{pH}$ values up to 8.2 (not shown), but light scattering is observed at higher $\mathrm{pH}$, consistent with fibril bundling as the molecular charge on the peptide begins to approach zero. Gel formation occurs before the $\mathrm{pH}$ change is complete, but the slow rate of $\mathrm{pH}$ change allows a handling window of several minutes for the peptide solutions prior to gelation, a property that may be useful in clinical settings. Overnight exposure of the gels to a $5 \% \mathrm{CO}_{2}$ atmosphere in a mammalian cell incubator lowered the $\mathrm{pH}$ by approximately 0.4-0.5 pH units (as observed by color change of phenol red), but an appropriate concentration of bicarbonate could be chosen to allow the preparation of gels with a $\mathrm{pH}$ suited to cell culture studies. Similar kinetic results were obtained for AFD36 gels prepared by the addition of bicarbonate in Dulbecco's modified Eagle medium (DMEM), allowing sample preparation for tissue culture experiments. Similarly, gel preparation using $10 \mathrm{mM}$ MES-bicarbonate buffer allowed sample characterization by ECD (below) while minimizing interference by salt.

\section{Thermal stability of AFD36 helices and gels}

Thermal denaturation studies were carried out to determine the heat stability of self-assembled AFD36 structures. This was done both in terms of primary (coiled coil) and secondary (gel) assembly, and showed gel melting to occur independently to $\alpha$ helix denaturation. Fig. 7 shows the effects of temperature on AFD36 helix content, as determined by ECD. At $20^{\circ} \mathrm{C}$, the mean residue ellipticity at $222 \mathrm{~nm}$ is $-30100 \mathrm{deg} \mathrm{cm}^{2} \mathrm{dmol}^{-1}$ for a gelled sample at $\mathrm{pH}$ 7.0. On heating to $90^{\circ} \mathrm{C}$, the mean residue ellipticity decreases to $-25500 \mathrm{deg} \mathrm{cm} \mathrm{dmol}^{-1}$, indicating that the temperature of half-denaturation ("melting temperature") is well in excess of $100{ }^{\circ} \mathrm{C}$. Cooling to $20^{\circ} \mathrm{C}$ results in recovery of most, but not all, of the original helical content, giving a final value of $[\theta]_{222}$ of $-28800 \mathrm{deg} \mathrm{cm}^{2} \mathrm{dmol}^{-1}$. Compared to the helical content, the macroscopic gel structure of AFD36 is less stable. A ball drop test showed a gel-sol transition temperature $\left(T_{\mathrm{m}}\right)$ of close to $80^{\circ} \mathrm{C}$ for an AFD36 gel prepared in $10 \mathrm{mM}$ MES buffer, although this increased to $90{ }^{\circ} \mathrm{C}$ for a gel prepared in phosphate-buffered saline at higher ionic strength. The disparity between the ECD and gel transition temperatures suggests that the gel-sol transition may occur by loss of the physical cross-links between the fibrils, as opposed to loss of the helical structure. Alternately, the slight decrease in helix content may lead to shortening of the fibril segments with loss of an overall network structure. In either case, the thermal transition for the AFD36 gel lies well above physiological temperatures, which is promising for potential biomedical applications.

\section{Thermodynamics of coiled-coil assembly}

Guanidinium chloride (G.HCl) denaturation studies on AFD36 and AFD19 were used to quantify the stability of these two peptide systems under weak gel-forming conditions (i.e., low concentration at $\mathrm{pH} 5.0$ for AFD19 and $\mathrm{pH} 6.0$ for AFD36). Details of these experiments are in the ESI. $\dagger$ Thermodynamic parameters for peptide self-assembly were determined by fitting helical content (measured by ECD; Fig. S1 $\dagger$ ) to monomeroligomer models. These data showed both AFD36 and AFD19 to have extremely high thermodynamic stabilities of 9.3 and $9.5 \mathrm{k} \mathrm{cal} \mathrm{mol}{ }^{-1}$ per monomer at $20{ }^{\circ} \mathrm{C}$ for a hexamer model, respectively. Furthermore, variations in the assumed oligomerization state from $n=5-12$, used in the thermodynamic modelling, resulted in only small changes in calculated stability, from 9.1 to $9.5 \mathrm{k} \mathrm{cal} \mathrm{mol}^{-1}$ per monomer for AFD36 (Table S1 $\dagger$ ). This indicated calculated stability values to be relatively insensitive to assumed oligomerization state. While this means such analysis is unable to explicitly determine coiled-coiled oligomerization state, even in the absence of such knowledge calculated stability values may be compared to previous published findings. These values are larger than reported for comparable systems, ${ }^{41}$ likely due to high average helix propensity. In addition, the expansion of the hydrophobic core to include positions $e$ and $g$ is a key factor in the designs of AFD19 and AFD36 and likely contributes to the high thermodynamic stability by increasing the hydrophobic driving force for assembly. This is further supported by the increased stability of $10.6 \mathrm{k} \mathrm{cal} \mathrm{mol}^{-1}$ per monomer of AFD36 when G.HCl denaturation was conducted at $50{ }^{\circ} \mathrm{C}$ (Table S1†), where such hydrophobic forces may be enhanced.

\section{Gel rheology}

Rheology was used to confirm the formation of robust gels using sodium bicarbonate titration. Furthermore, it has been shown that cell growth and function are impacted by the mechanical properties of the underlying substrate. ${ }^{71-73}$ The storage $\left(G^{\prime}\right)$ and loss $\left(G^{\prime \prime}\right)$ moduli of a gelling peptide solution were recorded using oscillatory shear rheology as the $\mathrm{pH}$ rose with loss of $\mathrm{CO}_{2}$ from the sample following addition of bicarbonate, allowing observation of the rate of network formation (Fig. 8A). A viscoelastic solid $\left(G^{\prime}>G^{\prime \prime}\right)$ was formed in the time taken to mix and load the sample and structure development then followed approximately first order kinetics. After 60 minutes the value of $G^{\prime}$ was $350 \mathrm{~Pa}$, indicating mechanical properties similar to soft tissues such as brain and lymph node. ${ }^{74}$ Few hydrogels based on coiled coils have been reported and only a small number have been investigated using rheology ${ }^{16}$ Comparison of AFD36 gels to published $\beta$-sheet peptide systems show comparable properties at similar or lower weight concentrations. ${ }^{75,76}$

After one hour, the formed gel showed moderate frequency dependence of $G^{\prime}$ and $G^{\prime \prime}$ (Fig. 8B). However, no cross-over point was observed, with $G^{\prime}$ being greater than $G^{\prime \prime}$ by at least at order of magnitude at all frequencies tested. At the completion of testing, visual observations of $\mathrm{pH}$-dependent color change showed the peptide sample to be lower than physiological $\mathrm{pH}$, 
likely due to limitations to the loss of $\mathrm{CO}_{2}$ at the plate edge. The results obtained are thus likely to represent a low-end estimate of the rate of gelation and the final gel strength.

\section{Mammalian cell culture on peptide gels}

As a proof of concept to assess the ability of AFD36 hydrogels to support mammalian cell growth, NIH/3T3 cells were cultured for 4 days on either tissue culture polystyrene (TCPS) or AFD36 gels pre-equilibrated with serum-free growth medium. Cell growth was quantified by AlamarBlue assay at each day, with cell images recorded at day 3 (Fig. 9). The fibroblasts proliferated well on AFD36 hydrogels, with cell growth at $68 \%$ of TCPS levels at day 4 , a level of growth similar to that seen with $\beta$ hairpin peptide gels. ${ }^{77,78}$ The fibroblasts adopted spread morphologies on AFD36 gels similar to the TCPS surface. Adhesion and spreading may be due to non-specific protein adsorption from serum onto the surface of the hydrogels, providing cellular attachment points. The lack of toxicity and observation of cellular proliferation suggest that the peptide gels have potential as biomaterials for tissue engineering applications.

\section{Conclusions}

In the present work, we show that simple design algorithms yield a short $\alpha$-helical peptide that forms responsive fibrils and hydrogels at physiological $\mathrm{pH}$ and salt. The generality of the fibril design approach reported here has not yet been fully tested, but it is clearly broad. Suitable thermodynamic analysis may be able to distinguish between sequences that will or will not support fibril formation, and we are currently developing a predictive model to this end.

Low-weight gels were formed uniformly by utilizing a simple methodology of transient buffering by carbonic acid to obtain physiological $\mathrm{pH}$. The coiled-coil state was confirmed by ECD, with fibril formation investigated via SAXS and AFM. Nanofibrils were observed possessing diameters consistent with a cross-section of 5-7 monomers per coiled-coil, with a low persistence length and high aspect ratio. The resulting gels are highly thermostable, with melting temperatures exceeding $80{ }^{\circ} \mathrm{C}$ as shown by ECD and ball drop tests. Characterization of the peptide hydrogel's mechanical properties via rheology show a weak viscoelastic solid comparable with soft tissues. Fibroblast cell culture showed spread morphologies with some cellular proliferation, providing a proof of principle for the capability of these peptide hydrogels for use as a mammalian cell growth platform. The peptide hydrogels offer a potential pathway for drug and/or cell delivery in a biocompatible matrix, in addition to providing insights into protein aggregation, which in turn may provide for greater understanding of related disease states.

\section{Acknowledgements}

This research was facilitated by access to the Australian Proteome Analysis Facility and the Queensland node of the
Australian National Fabrication Facility, a company established under the National Collaborative Research Infrastructure Strategy to provide nano- and micro-fabrication facilities for Australia's researchers. This work was carried out in part in the Centre for Microscopy and Microanalysis at The University of Queensland, the Queensland node of the Australian Microscopy and Microanalysis Research Facility (AMMRF). Financial support was provided by the Australian Research Council (Grant IDs FT0991283, DP0987407 and DP150100268).

\section{References}

1 A. M. Jonker, D. W. P. M. Lowik and J. C. M. van Hest, Chem. Mater., 2012, 24, 759-773.

2 Y. L. Li, J. Rodrigues and H. Tomas, Chem. Soc. Rev., 2012, 41, 2193-2221.

3 E. Caló and V. V. Khutoryanskiy, Eur. Polym. J., 2015, 65, 252267.

4 T. Delair, Carbohydr. Polym., 2012, 87, 1013-1019.

5 D. Macaya and M. Spector, Biomed. Mater., 2012, 7, 22.

6 E. R. Aurand, K. J. Lampe and K. B. Bjugstad, Neurosci. Res., 2012, 72, 199-213.

7 E. Lallana, F. Fernandez-Trillo, A. Sousa-Herves, R. Riguera and E. Fernandez-Megia, Pharm. Res., 2012, 29, 902-921.

8 M. C. Branco and J. P. Schneider, Acta Biomater., 2009, 5, 817-831.

9 B. Balakrishnan, M. Mohanty, P. R. Umashankar and A. Jayakrishnan, Biomaterials, 2005, 26, 6335-6342.

10 W. K. Loke, S. K. Lau, L. L. Yong, E. Khor and C. K. Sum, J. Biomed. Mater. Res., 2000, 53, 8-17.

11 F. Yang, C. G. Williams, D. A. Wang, H. Lee, P. N. Manson and J. Elisseeff, Biomaterials, 2005, 26, 5991-5998.

12 N. A. Peppas, Y. Huang, M. Torres-Lugo, J. H. Ward and J. Zhang, Annu. Rev. Biomed. Eng., 2000, 2, 9-29.

13 A. N. Buxton, J. Zhu, R. Marchant, J. L. West, J. U. Yoo and B. Johnstone, Tissue Eng., 2007, 13, 2549-2560.

14 Y. Q. Tang, C. L. Heaysman, S. Willis and A. L. Lewis, Expert Opin. Drug Delivery, 2011, 8, 1141-1159.

15 L. A. Estroff and A. D. Hamilton, Chem. Rev., 2004, 104, 12011217.

16 E. F. Banwell, E. S. Abelardo, D. J. Adams, M. A. Birchall, A. Corrigan, A. M. Donald, M. Kirkland, L. C. Serpell, M. F. Butler and D. N. Woolfson, Nat. Mater., 2009, 8, 596600.

17 A. Aggeli, M. Bell, N. Boden, J. N. Keen, P. F. Knowles, T. C. B. McLeish, M. Pitkeathly and S. E. Radford, Nature, 1997, 386, 259-262.

18 A. Aggeli, M. Bell, L. M. Carrick, C. W. G. Fishwick, R. Harding, P. J. Mawer, S. E. Radford, A. E. Strong and N. Boden, J. Am. Chem. Soc., 2003, 125, 9619-9628.

19 L. Haines-Butterick, K. Rajagopal, M. Branco, D. Salick, R. Rughani, M. Pilarz, M. S. Lamm, D. J. Pochan and J. P. Schneider, Proc. Natl. Acad. Sci. U. S. A., 2007, 104, 7791-7796.

20 A. Dasgupta, J. H. Mondal and D. Das, RSC Adv., 2013, 3, 9117-9149. 
21 K. Chockalingam, M. Blenner and S. Banta, Protein Eng., Des. Sel., 2007, 20, 155-161.

22 C. Y. Xu, V. Breedveld and J. Kopecek, Biomacromolecules, 2005, 6, 1739-1749.

23 G. Fichman and E. Gazit, Acta Biomater., 2014, 10, 16711682.

24 S. G. Zhang, T. Holmes, C. Lockshin and A. Rich, Proc. Natl. Acad. Sci. U. S. A., 1993, 90, 3334-3338.

25 M. R. Caplan, P. N. Moore, S. G. Zhang, R. D. Kamm and D. A. Lauffenburger, Biomacromolecules, 2000, 1, 627-631.

26 R. G. Ellis-Behnke, Y. X. Liang, S. W. You, D. K. C. Tay, S. G. Zhang, K. F. So and G. E. Schneider, Proc. Natl. Acad. Sci. U. S. A., 2006, 103, 5054-5059.

27 D. A. Narmoneva, O. Oni, A. L. Sieminski, S. G. Zhang, J. P. Gertler, R. D. Kamm and R. T. Lee, Biomaterials, 2005, 26, 4837-4846.

28 J. J. Panda and V. S. Chauhan, Polym. Chem., 2014, 5, 4431.

29 C. Vepari and D. L. Kaplan, Prog. Polym. Sci., 2007, 32, 9911007.

30 F. Chiti and C. M. Dobson, Annu. Rev. Biochem., 2006, 75, 333-366.

31 F. E. Cohen and S. B. Prusiner, Annu. Rev. Biochem., 1998, 67, 793-819.

32 M. E. Oskarsson, J. F. Paulsson, S. W. Schultz, M. Ingelsson, P. Westermark and G. T. Westermark, Am. J. Pathol., 2015, 185, 834-846.

33 K. Hartman, J. R. Brender, K. Monde, A. Ono, M. L. Evans, N. Popovych, M. R. Chapman and A. Ramamoorthy, PeerJ, 2013, 1, e5.

34 P. Westermark, K. Lundmark and G. T. Westermark, PLoS One, 2009, 4, e6041.

35 D. N. Woolfson, Biopolymers, 2010, 94, 118-127.

36 N. L. Fletcher, C. V. Lockett and A. F. Dexter, Soft Matter, 2011, 7, 10210-10218.

37 T. N. Melnik, V. Villard, V. Vasiliev, G. Corradin, A. V. Kajava and S. A. Potekhin, Protein Eng., 2003, 16, 1125-1130.

38 T. Takei, K. Hasegawa, K. Imada, K. Namba, K. Tsumoto, Y. Kuriki, M. Yoshino, K. Yazaki, S. Kojima, T. Takei, T. Ueda and K.-I. Miura, Biochemistry, 2013, 52, 2810-2820.

39 A. F. Dexter, Langmuir, 2010, 26, 17997-18007.

40 C. A. Dreiss, K. S. Jack and A. P. Parker, J. Appl. Crystallogr., 2006, 39, 32-38.

41 R. Fairman, H. G. Chao, L. Mueller, T. B. Lavoie, L. Y. Shen, J. Novotny and G. R. Matsueda, Protein Sci., 1995, 4, 14571469.

42 J. K. Myers, C. N. Pace and J. M. Scholtz, Protein Sci., 1995, 4, 2138-2148.

43 J. M. Scholtz, H. Qian, E. J. York, J. M. Stewart and R. L. Baldwin, Biopolymers, 1991, 31, 1463-1470.

44 P. J. Gans, P. C. Lyu, M. C. Manning, R. W. Woody and N. R. Kallenbach, Biopolymers, 1991, 31, 1605-1614.

45 D. N. Woolfson, G. J. Bartlett, M. Bruning and A. R. Thomson, Curr. Opin. Struct. Biol., 2012, 22, 432-441.

46 D. A. D. Parry, R. D. B. Fraser and J. M. Squire, J. Struct. Biol., 2008, 163, 258-269.
47 J. Liu, Q. Zheng, Y. Q. Deng, C. S. Cheng, N. R. Kallenbach and M. Lu, Proc. Natl. Acad. Sci. U. S. A., 2006, 103, 1545715462.

48 S. A. Potekhin, T. N. Melnik, V. Popov, N. F. Lanina, A. A. Vazina, P. Rigler, A. S. Verdini, G. Corradin and A. V. Kajava, Chem. Biol., 2001, 8, 1025-1032.

49 N. R. Zaccai, B. Chi, A. R. Thomson, A. L. Boyle, G. J. Bartlett, M. Bruning, N. Linden, R. B. Sessions, P. J. Booth, R. L. Brady and D. N. Woolfson, Nat. Chem. Biol., 2011, 7, 935-941.

50 C. F. Xu, R. Liu, A. K. Mehta, R. C. Guerrero-Ferreira, E. R. Wright, S. Dunin-Horkawicz, K. Morris, L. C. Serpell, X. B. Zuo, J. S. Wall and V. P. Conticello, J. Am. Chem. Soc., 2013, 135, 15565-15578.

51 J. Liu, Q. Zheng, Y. Q. Deng, N. R. Kallenbach and M. Lu, J. Mol. Biol., 2006, 361, 168-179.

52 P. B. Harbury, T. Zhang, P. S. Kim and T. Alber, Science, 1993, 262, 1401-1407.

53 B. Apostolovic, M. Danial and H. A. Klok, Chem. Soc. Rev., 2010, 39, 3541-3575.

54 C. Vu, J. Robblee, K. M. Werner and R. Fairman, Protein Sci., 2001, 10, 631-637.

55 M. J. Pandya, G. M. Spooner, M. Sunde, J. R. Thorpe, A. Rodger and D. N. Woolfson, Biochemistry, 2000, 39, 8728-8734.

56 D. Papapostolou, A. M. Smith, E. D. T. Atkins, S. J. Oliver, M. G. Ryadnov, L. C. Serpell and D. N. Woolfson, Proc. Natl. Acad. Sci. U. S. A., 2007, 104, 10853-10858.

57 M. G. Ryadnov and D. N. Woolfson, Nat. Mater., 2003, 2, 329332.

58 Y. Zimenkov, V. P. Conticello, L. Guo and P. Thiyagarajan, Tetrahedron, 2004, 60, 7237-7246.

59 Y. Zimenkov, S. N. Dublin, R. Ni, R. S. Tu, V. Breedveld, R. P. Apkarian and V. P. Conticello, J. Am. Chem. Soc., 2006, 128, 6770-6771.

60 S. Kojima, Y. Kuriki, T. Yoshida, K. Yazaki and K. Miura, Proc. Jpn. Acad., Ser. B, 1997, 73, 7-11.

61 H. Dong, S. E. Paramonov and J. D. Hartgerink, J. Am. Chem. Soc., 2008, 130, 13691-13695.

62 S. Y. M. Lau, A. K. Taneja and R. S. Hodges, J. Biol. Chem., 1984, 259, 3253-3261.

63 N. E. Zhou, C. M. Kay and R. S. Hodges, J. Biol. Chem., 1992, 267, 2664-2670.

64 B. Heitmann, G. E. Job, R. J. Kennedy, S. M. Walker and D. S. Kemp, J. Am. Chem. Soc., 2005, 127, 1690-1704.

65 A. R. Kirby, V. J. Morris and A. Patrick Gunning, in Atomic Force Microscopy for Biologists, Imperial College Press, 2nd edn, 2012.

66 S. J. Opella, F. M. Marassi, J. J. Gesell, A. P. Valente, Y. Kim, M. Oblatt-Montal and M. Montal, Nat. Struct. Biol., 1999, 6, 374-379.

67 V. N. Malashkevich, R. A. Kammerer, V. P. Efimov, T. Schulthess and J. Engel, Science, 1996, 274, 761-765.

68 Y. Lu, B. Weers and N. C. Stellwagen, Biopolymers, 2002, 61, 261-275.

69 C. C. vandenAkker, M. F. M. Engel, K. P. Velikov, M. Bonn and G. H. Koenderink, J. Am. Chem. Soc., 2011, 133, 1803018033. 
70 A. Aggeli, I. A. Nyrkova, M. Bell, R. Harding, L. Carrick, T. C. B. McLeish, A. N. Semenov and N. Boden, Proc. Natl. Acad. Sci. U. S. A., 2001, 98, 11857-11862.

71 S. R. Peyton, C. M. Ghajar, C. B. Khatiwala and A. J. Putnam, Cell Biochem. Biophys., 2007, 47, 300-320.

72 M. D. Stevenson, H. Piristine, N. J. Hogrebe, T. M. Nocera, M. W. Boehm, R. K. Reen, K. W. Koelling, G. Agarwal, A. L. Sarang-Sieminski and K. J. Gooch, Acta Biomater, 2013, 9, 7651-7661.

73 A. S. Rowlands, P. A. George and J. J. Cooper-White, Am. J. Physiol.: Cell Physiol., 2008, 295, C1037-C1044.
74 J. H. Collier, J. S. Rudra, J. Z. Gasiorowski and J. P. Jung, Chem. Soc. Rev., 2010, 39, 3413-3424.

75 B. Ozbas, K. Rajagopal, J. P. Schneider and D. J. Pochan, Phys. Rev. Lett., 2004, 93, 268106.

76 C. Cunha, S. Panseri, O. Villa, D. Silva and F. Gelain, Int. J. Nanomed., 2011, 6, 943-955.

77 L. A. Haines, K. Rajagopal, B. Ozbas, D. A. Salick, D. J. Pochan and J. P. Schneider, J. Am. Chem. Soc., 2005, 127, 17025-17029.

78 J. K. Kretsinger, L. A. Haines, B. Ozbas, D. J. Pochan and J. P. Schneider, Biomaterials, 2005, 26, 5177-5186. 